\title{
Philosophy of Technoscience in the Regime of Vigilance
}

\author{
Alfred Nordmann \\ In Graeme Hodge, Diana Bowman, Andrew Maynard (eds.) \\ International Handbook on Regulating Nanotechnologies \\ Cheltenham: Edward Elgar, 2010, pp. 25-45
}

A prominent, perhaps defining feature of 'nanotechnology' is its interest from the very beginning to evaluate its own promise and peril. ${ }^{1}$ As Arie Rip has pointed out, this has produced a kind of 'division of moral labor' which is perhaps not unlike the division of labor between physicists who develop analytic tools and chemists who investigate properties of matter (Shelley-Egan and Rip, 2009). As in all divisions of labor, one often does not and perhaps need not know very much about the problems and methods that guide the work on the other side of the divide. On the side of scientists and policy makers there appears to be a tacit agreement that philosophy can be equated with ethics, that philosophers articulate widely shared concerns, and that lists of issues regarding the safety and social implications of nanotechnology create a kind of interface with larger publics. Indeed, the participation of a philosopher in a nanotech conference sometimes serves as a stand-in for the inclusion of society at large.

There is much to be said about this caricature of what philosophers can and cannot contribute by way of reflection on emerging technologies. Here, a strong case is made for the role of the philosophy of science or, more precisely, the philosophy of technoscience. Rather than leap ahead to ethical issues, the philosophy of technoscience reflects what 'nanotechnology' is. This understanding is a precondition for the identification and consideration of ethical, societal, and regulatory issues. In particular, then, this chapter aims to show how specific challenges to the

\footnotetext{
${ }^{1}$ This is an area of common ground between the visionary pioneers of nanotechnology and various policy initiatives all over the world, for some early examples see Roco and Bainbridge (2001), Roco and Tomellini (2002), or Roco (2003).
} 
regulation of nanotechologies arise from the very nature of nanotechnology and nanotechnological research. ${ }^{2}$

What 'nanotechnology' is cannot be learned from scientific definitions, for example, regarding the discovery, understanding, and technological potential of scale-dependently discontinuous properties at the nanoscale. Instead of asking for a definition, one might ask questions like these:

1. Where does nanotechnology come from?

2. What is the relation between science and technology in the case of nanotechnologies and, in particular, what kind of knowledge underwrites nanotechnological developments?

3. What does it take to control properties and processes at the nanoscale and what is special about the objects that are encountered and constructed in nanotech laboratories?

4. What are the scientific and technological mindsets of those who pursue more or less pronounced visions of technical control at the molecular level, and how do these compare to the implicit ideals that guide traditional pursuits of chemistry, materials science, physics, molecular biology or semiconductor research?

By way of introduction, a very brief review of four philosophical questions serves to illustrate how from a basic understanding of 'nanotechnoscience' one can begin to see salient societal and ethical dimensions. Though some of these touch on regulatory issues already, the second part of this chapter will explore rather more specific connections between nanotechnoscience and the regime of vigilance that is required for monitoring and regulating it. This will culminate in a proposal for a type of governance and a type of agency which is based on this understanding.

\section{Philosophy of NANOTECHNOSCIENCE 3}

Although it sounds somewhat contrived, the term 'nanotechnoscience' serves well to express the difficulty of distinguishing between nanoscience and nanotechnology. Of course, much nanotechnological research is very fundamental and far removed from practical applications. Moreover, a great deal of scientific knowledge and experience goes into the acquisition of basic capabilities to visualise and manipulate, to model and functionalise novel nanoscale phenomena.

\footnotetext{
${ }^{2}$ Of course, there is no such thing as a unified and coherent 'nanotechnology' in the singular. However, the persistence of the expression in the singular is itself part of the 'nanotechnology phenomenon' (see Hodge, Bowman and Maynard in the Introduction to this volume). The term in the singular highlights some general features which pose regulatory challenges: heterogeneity of processes and products, limits of understanding and technical control at the nanoscale, and problems of foresight.

${ }^{3}$ This section provides a brief synopsis and adopts some of its formulations from Alfred Nordmann (2008a).
} 
Nevertheless, this research does not fit standard conceptions of 'science' because the point of its investigations is not normally to question received views and to establish new truths, nor is it to produce conjectures and then try to falsify them, or to develop theories that close important gaps in our understanding of the world. Inversely, even though nanoscale research practice involves a good bit of tinkering and pursues technological challenges and promises, it is also not 'engineering' because most researchers are not in the business of building devices for more or less immediate use. At best, they lay the groundwork for concrete engineering projects in the future. Nanotechnological research is therefore somewhere 'in between' science and technology and has been described by Peter Galison (2006: 1) as an 'engineering way of being in science'.

For much of the nineteenth and twentieth centuries the philosophy of science addressed some very general questions about physics, chemistry and biology. Often scientists and philosophers engaged in this together, philosophical reflection serving purposes internal to each of these fields by strengthening a sense of disciplinary identity. Similarly, the philosophy of technoscience addresses foundational questions to nanotechnological research. Four questions might make a beginning:

1. What is the role of theory and theory-development in nanoscale research, and what kinds of theories are needed for nanotechnological development?

2. What are the preferred modes of reasoning and methods and associated tools in nanoscientific research?

3. How is the domain of objects of nanotechnoscience constituted?

4. What kind of knowledge do technoscientific researchers typically produce and communicate?

5.

In all four cases, strictly philosophical considerations shade into societal dimensions and questions of value with implications also for regulatory questions. ${ }^{4}$ So, what is meant by each of these questions?

\section{a) Theories as Tools}

The philosophy of nanotechnoscience needs to come to terms with a fundamental tension that informs the very idea of nanotechnology. Indeed, without this tension nanotechnology would be

\footnotetext{
${ }^{4}$ It should be noted, however, that the philosophy of technoscience is a new endeavor in its own right. What in the following is presented as findings of a philosophy of nanotechnoscience has not been subjected as of yet to the kind of rigorous debate that is characteristic of the philosophy of science. Accordingly, the following analyses provide a rough and preliminary sketch.
} 
impossible and uninteresting. The intellectual and technical challenge posed by the control of nanoscale processes and properties consists in the fact that there is novelty and surprise at the nanoscale which owes largely to the features of the nanocosm as an intermediary realm between the worlds of classical and quantum physics or chemistry. On the one hand, this novelty and surprise results from the fact that each in their own way, classical and quantum theories do not quite account for processes and events at the nanoscale. On the other hand, the available theories and techniques are considered resourceful enough when it comes to modeling or explaining what goes on at the nanoscale.

A characteristic tension concerning nanotechnology as a whole is therefore mirrored in an analogous tension regarding available theories. Nanotechnology is thought to be strange, novel, and surprising on the one hand, familiar and manageable on the other. The available theories are thought to be inadequate on the one hand but quite sufficient on the other. The profound difference between classical and quantum regimes highlights what makes the nanocosm special and interesting - but this difference melts down to a matter of expediency and taste when it comes to choosing tools from classical or quantum physics (Nordmann, 2004). Put yet another way: What makes nanoscale phenomena scientifically interesting is that they cannot be adequately described from either perspective, but what makes nanotechnologies possible is that the two perspectives make do when it comes to account for these phenomena.

Nanotechnology thus appears as a technology that is not based on or grounded in theories that are predictively adequate to the phenomena at the nanoscale. Instead, it uncovers novelty and surprise and then proceeds to show that the available toolbox of theories is big enough to allow for modeling or explaining the novel processes and surprising phenomena. It is easy to see that this has implications for regulatory ambitions. Most everyone approaches nanotechnological unknowns on the assumption that known frameworks, theories and techniques can be stretched far enough to sufficiently account for the unknown. By wagering on this, one tends to be slow, even reluctant to acknowledge that one just doesn't have and perhaps will never have the knowledge that would be required. Currently, the case of nanotoxicology exemplifies this pattern all too well. Readers of the Introduction to this volume will notice how swiftly one moves from the conceptual simplicity of applying a conventional risk assessment paradigm to the qualification that definitive answers might be years away and available only on a case-by-case basis. And it then turns out that this sobering insight is only the first in a dauntingly long list of rather principled difficulties that call into question, for example, the adequacy of stretching mass-based regulatory approaches to nanoparticles. At the end of that list, the initial conceptual simplicity has all but dissolved. All this 
suggests that demands for the regulation of nanoparticles as chemicals are short-changed in two ways: On the one hand, there is insufficient data, on the other hand, there is not yet enough reflection on those fundamental barriers that might require a whole new approach - what is most needed, perhaps, is a very frank acknowledgment that it is not an option to wait for the kind of knowledge that everyone is waiting for in order to apply the conventional risk assessment paradigm. On the basis of this acknowledgment, one might then develop more appropriate alternative approaches.

\section{b) Qualitative Reasoning}

Another essential endeavor of any philosophy of technoscience is the analysis of methods - what are the characteristic methods of nanotechnological research and how well do they work? Following immediately on the reflections about the role of theory, one can note that despite its strong debt to physics, chemistry, or biology, this research follows a qualitative and not a quantitative methodology.

Here, 'quantitative' means more than the employment of numbers and even of precision measurements. Two characteristics, in particular, may serve to define a quantitative method: First, predicted numerical values are compared to values obtained by measurement. The reasonably close agreement between two numbers thus serves to establish the agreement of theory and reality. Second, this quantitative agreement emphatically makes do without any appeal to a likeness or similarity between theoretical models and the real-world systems they are said to represent. Quantitative science rests content if it reliably leads from initial conditions to accurate predictions. It does not require that every detail of its conceptual apparatus (every term in its algorithms) has a counterpart in reality. Both characteristics of quantitative science are familiar especially from twentieth century theoretical physics - but do they also serve to characterise nanotechnoscience?

A general answer may not be possible here. But it can be shown that a very prominent approach to the investigation of nanoscale phenomena does not fit this description of quantitative method. This approach involves the construction in the laboratory ('in vitro/in vivo') of a so-called apparatus-world complex that affords, for example, the controlled growth of carbon-nanotubes (Harré, 2003). And then one constructs in a computer ('in silico') another apparatus-world complex that affords a 'calculated image' or simulation of the behavior of the carbon-nanotubes. The likeness between experimental and calculated images, between in vivo and in silico situations is taken to be a significant achievement. It is to signify that the experiment and the simulation follow the same 
dynamic. Supposedly, the likeness is not just accidental or even illusory: if two systems exhibit the same behavior, they are thought to share in the same reality. In other words, the visualised behavior that is pieced together from familiar algorithms and bits of theory in a computer simulation is taken to explain the material behavior in the laboratory. The simulation thus serves the purpose of explanation just to the extent that the observable likeness of the two behaviors indicatess that both systems express the same dynamics, that they have a natural kinship in that they participate in the same underlying reality.

Again, this all too brief philosophical characterisation of method has obvious implications well beyond the narrow confines of philosophy. Both of these implications are not normally considered to be of regulatory relevance or concern, but they shape public perceptions and understanding of nanotechnology to such an extent that they can produce unrealistic expectations of what regulation can deliver.

First, qualitative reasoning that is stimulated by visual likeness draws our attention to the power of images and of the visual in nanotechnology. Indeed, by shifting from quantitative coordinations of numerical values to the construction of qualitative likeness, from the conventional representation of reality to the symbolic substitution of one reality by another, nanotechnoscience has become beholden to the power of images. It is fairly easy to see that images from the nanocosm are at this point still the most impressive as well as popular nanotechnological products. Art historians and theorists like William Mitchell (2005) or Hans Belting (2001), in particular, have emphasised the difference between: i) conventional signs that serve the purpose of representation, and ii) pictures or images that embody visions and desires, that cannot be controlled in that they are not mere vehicles of information but produce an excess of meaning that is not contained in a conventional message. For example, it is commonly maintained that nanosized things consist only of surface and have no bulk. This is what makes them intellectually and technically interesting. But pictures of the nanocosm invariably show objects with very familiar bulk-surface proportions, a world that looks perfectly suited for conventional technical constructions. Thus, once again we might be facing the predicament that our way of grasping at the nanoscale and our way of imagining it may foster an illusion of technical as well as regulatory control. Images show us only what agrees with our visual expectations that have been trained at a macroscopic scale, they do not normally reflect upon themselves or lead us to question what we see. Relying very much on imagery to make sense of nanotechnology, we do not learn what the limits of nanotechnical constructions and control might be, but think it quite ordinary like any other technology. 
Second, when the likeness or similarity of two things is taken to be a deeply meaningful token of a natural kinship, philosophers and historians of science tend to relate this to prescientific magical thinking. The pseudo-science of physiognomy, for example, is based on the idea that there is a meaningful likeness between the facial features and the character of a person. Voodoo-practitioners may want to cause harm to a person by sticking needles in a doll, and they do so upon the conviction that the person is somehow in the doll and that the doll participates in the reality of the person (Nordmann, 2006a). The magical thinking of nanoscientists is much more trustworthy and robust than all that, of course. ${ }^{5}$ And yet, this draws attention to a variety of ways nanotechnoscience and its associated imagery cultivate a magical relation to technology. It can be said, for example, that in the earlier days of humankind people were confronted with an enchanted and uncanny nature that needed to be soothed by praying to the spirits that dwelled in rocks and trees. Modern science and technology tamed and rationalised nature in a piece-meal fashion. Technology represents the extent to which we managed to defeat a spirited, enchanted world and subjected it to our control we technologised nature. In the age of nanotechnoscience, however, visitors of science museums are invited to marvel at engineering feats, to imagine the incredible tininess of nano and a kind of technological agency well beneath the threshold of human perception or experience. We are also invited to pin societal hopes for technological innovation on the creation of systems that display a dynamics as inscrutable and complex as that of natural systems - it appears that we set out to naturalise technology. However, to naturalize technology would amount to replacing rational control over brute environments by dependency on mysterious functioning of smart environments. We may thus end up rendering technology just as uncanny as nature used to be with its earthquakes, diseases, thunderstorms (Nordmann, 2006b, 2008). ${ }^{6}$

To the extent that the regulation of substances, processes, and products aims for public oversight, political transparency and legal certainty, it needs to countenance and, if need be, to offer correctives to a view of nanotechnology that is shaped by images that tend to overwhelm critical thinking and that mostly marvels at all that nanotechnology might be able to do.

\footnotetext{
${ }^{5}$ It is one of the tasks of the philosophy of nanotechnoscience, however, to explicate what warrants this kind of reasoning.

6 This is a strong indictment not of particular nanotechnologies but of certain ways of propagating our nanotechnological future. Considered another way, it is simply an engineering challenge to design nanotechnology for the human scale.
} 


\section{c) Domain of Objects}

Any field of research is directed at a certain domain of objects and what unifies this domain is a particular way of conceiving these objects. Mechanics, for example, looks at all phenomena of motion and everything that can be assigned coordinates in time and space and that has mass becomes the object of mechanics and is of interest only in regard to those properties that make it an object of motion. The philosophy of science articulates this world-view of mechanics and asks, for example, to what extent certain conceptions of time and space prejudice the investigation of objects in motion. If one now asks about nanotechnological research, the philosophy of technoscience may offer something like the following characterisation of its domain of objects: Nanotechnological research considers properties, traits, or features in regard primarily to their potential to serve a technical function, and in regard only incidentally to structure.

Clearly this requires elaboration and perhaps debate within the philosophy of technoscience, especially regarding the relation of property and underlying structure. For now, we can see the problems with this way of conceiving the objects of nanotechnology as they affect also regulatory interests: Nanotechnology opens an unlimited space of technical possibilities and thus presents itself as too amorphous and unwieldy for both political deliberation and, arguably, deliberate regulatory intervention. It is unlimited in two dimensions. First, the objects of nanotechnology do not have fixed and definite substantial natures but are mere potentials. Substantial natures determine what something is - a stone is hard as a rock. Considered as a mere potential, the stone is what it might become, that is, it is a momentary configuration of atoms and molecules that could be turned into just about anything else. ${ }^{7}$ Second, if one considers nanotechnology as concerned with a universe of lego-blocks that can be combined and recombined to 'shape the world atom by atom,' each given thing stands for an infinity of combinatorial possibilities that await to be realised in the future. ${ }^{8}$ Accordingly, when one talks of nanotechnology, people will point to nature's nanotechnology and some accomplishments of materials science as examples of what nanotechnology is, but they will always point out that these are mere signs for future developments. The 'real' nanotechnology and

\footnotetext{
7 The example of the stone is taken from a book by Gerd Binnig where he argues that from the point of view of nanotechnology, a stone has the potential to become anything else (Binnig, 1992).

8 Shaping the World Atom by Atom is not a slogan by Eric Drexler and proponents of far-fetched schemes for molecular manufacturing. It is the title of the brochure that was meant to introduce policy makers and the US-American public to the National Nanotechnology Initiative (Amato, 1999). With the notion of an unlimited space of combinatorial possibilities comes the transgressive character of nanotechnoscience which prompts many calls for regulation. Categorial distinctions of living and inanimate, organic and inorganic, biological and technical things, of nature and culture appear to become meaningless. This is so even though hardly any researcher believes literally in brain implants to expand human memory or in the infinite plasticity of everything molecular. The molecular point of view proves transgressive on a rather more elementary level, when, for example, biological cells are redescribed as factories with molecular nanomachinery.
} 
the nanotechnology that calls for regulation is almost by definition not something that can be known now but what is yet to come.

The particular objects of nanotechnology are elusive in that they lack a fixed nature - what makes them promising for technical applications also makes them unpredictable in regard to other potential effects which they might manifest when they interact in new ways with technical and biological systems. By the same token, nanotechnology as a whole becomes elusive, and we consequently become witness to shifts in what 'regulation' is supposed to be. As if the business of monitoring, of responsiveness, of the determination and enforcement of safety thresholds were not difficult enough, regulation is now called upon for preparedness, foresight, and anticipation. And in order to be anticipatory, regulation is drawn from products and manufacturing processes to research or even further upstream to visionary declarations of the ambition to interfere with nature in novel ways. $^{9}$

\section{d) Knowledge Claims}

What kind of knowledge does nanotechnoscience produce? With this question, the philosophy of technoscience inherits another problem from the philosophy of science and, once again, it needs to provide a distinctive account it differently. A very cursory answer must suffice for present purposes.

When one speaks of scientific knowledge, one usually means what is written down in textbooks or what represents the current consensus of scientists on a certain topic. In both cases, the knowledge that is produced by scientists consists in statements that are determined to be true or empirically adequate or rather likely to be true. Normally these statements get written down as theories or hypotheses, explanations and descriptions. In contrast, technoscientific knowledge consists in the acquisition and demonstration of basic capabilities of visualisation, manipulation, modelling, or construction. The typical scientific publication argues that here is evidence to confirm or disconfirm an hypothesis.' The typical technoscientific publication shows that 'here is what we accomplished in our laboratory.' For example, it is a major achievement in nanotechnoscience to do something at room temperature and in atmospheric conditions where others required extreme coldness in a vacuum.

If knowledge production in the technosciences consists in the development of capabilities but not in the advancement of intellectually transparent understanding, what one can do gets ahead of what is understood. In the seemingly rather different context of the nuclear arms race, the philosopher

\footnotetext{
${ }^{9}$ An example of this might be the attempt of the European Parliament to establish regulatory standards for nanofoods
} which run way ahead of current technical capabilities. 
Günter Anders used two Germans words to express this inverted order: herstellen [making] gets ahead of vorstellen [imagining] (Anders, 1972, 73 f., compare Anders, 1980). A great deal of scientific knowledge goes into the acquisition of new capabilities and a great deal goes into modelling it in some fashion. And yet, what is achieved can be technically robust while remaining intellectually opaque.

The standard example of technology running ahead of science is the steam engine which was developed without a proper understanding of the relation between heat and work (Baird, 2004). This understanding came much later and, indeed, was prompted in part by the efficient performance of the steam engine. Therefore, the steam engine itself cannot be considered applied science but was the result of technical tinkering. It was made of valves, pumps, flywheels, and gears of which there was very decent non-scientific craft-knowledge. And though it was assembled in such a piecemeal manner, the steam-engine worked just fine before the advent of thermodynamics. In a sense, it did not need to be understood since it was firmly rooted in the artisan and technical skills of an emerging industrial society. As opposed to the steam engine, nanotechnological devices (whatever they will be), genetically modified organisms, or drug delivery systems are rooted in an emerging knowledge society. They are not made of artisan valves and pumps but assembled from 'scientific' components such as algorithms, measuring and monitoring devices with plenty of knowledge built in, as well as the skills of academically educated engineers (Winsberg, 2006, 2009). The science that goes into algorithms or sensors is well-understood, as were the valves and gears of the eighteenth century. Of the interactions among all the components and of their sensitivities within the overall technical system one knows as little perhaps as about the relation of heat and work in the eighteenth century - there are theories and elementary conceptions, of course, but a steep learningcurve still ahead. And yet, like the steam-engine the nanotechnological devices or drug delivery systems may work just fine without being fully understood. And though one lacks positive knowledge from which to derive or predict the performance of these devices, it may well be possible to assess their robustness.

For regulatory purposes this might mean that one should not try to infer from knowledge of the components to the behavior of the system - that is, that the regulation of components or (chemical) substances perhaps ought to give way to the regulation of whole devices, products, or systems. If the toxicological effects of nanoparticles elude the grasp of knowledge and imagination, it might yet be possible to assess the soundness of a manufacturing process or the safety of a cleaning agent just as it was possible to define through trial and error the safe working of a steam-engine in the eighteenth century. 


\section{The Regime of Permanent Vigilance}

So far, this chapter entertained questions that have been associated traditionally with the philosophy of science. Having arrived at the notion that one may be able to assess the robustness of a system even in the absence of thorough understanding, a new set of questions appears belonging to the philosophy of experiment and the philosophy of technology.

\section{a) Collective Experimentation}

After debating theories and objects, knowledge and method, philosophers took an interest in scientific and technoscientific experiments. A traditional account of scientific experimentation will emphasise that in the experiment a theory or hypothesis is put to the test, and that this test will result in the confirmation or falsification of the hypothesis. More recent accounts attend to the technical difficulties and accomplishments of experiments. Quite independently of what experiments are used for, they consist first and foremost in the stabilisation of a phenomenon in a laboratory - experiments make something observable, measurable, and replicable that does not exist as such outside controlled laboratory conditions. This is surely what nanotechnological experiments do, too. Indeed, one might say that this experimental achievement is the beginning and end of nanotechnology (Nordmann, 2006c). When Don Eigler and Erhard Schweizer moved 35 xenon atoms to spell the letters I-B-M they referred to this as 'The Beginning' because they managed for the first time to make individual atoms obey a rather arbitrary and very human assignment. ${ }^{10}$ By doing so, they anticipated the most ambitious purpose or end of nanotechnology - namely to extend this kind of control to the construction of useful devices that could survive outside of the laboratory. Similarly, when Mark Reed and James Tour first passed in 1997 a current through a single organic molecule, they anticipated a new generation of computers with molecular wiring. And so with all the novel phenomena and surprising properties that are discovered in nanotechnological laboratories - they mark the beginning of a process of 'delocalization' (Galison, 1997). Phenomena leave their place of origin and become delocalised by being stabilised in the laboratory, then rendered robust enough to be reproducible under varying conditions in other laboratories, then scaled up and moved out of the laboratory altogether into the world at large of technical devices.

This process of delocalisation aims for a seamless transition from laboratory to market-place as technical processes or phenomena become more robust or viable. It is therefore misleading to

10 Eigler's and Schweizer's 'The Beginning' is on display at the Almaden STM-gallery. See http:// www.almaden.ibm.com/vis/stm/atomo.html 
imagine that these processes and phenomena are brought to completion in the scientific laboratory and then handed over or 'transferred' to engineers and commercial development. Instead, the world at large is just a bigger laboratory in which these processes and phenomena can prove themselves. This picture of technoscientific progress supports more general accounts of social experimentation with new technologies in society as a laboratory. According to these accounts, the consumers who eagerly buy the newest communication tools are engaged in a large-scale experiment that determines whether these gadgets undermine social cohesion or enhance effective information flows. Similarly, citizens who support public investment in nanotechnological research are engaged in a large-scale experiment that determines whether this kind of research leads to economic growth or to new environmental hazards. Consumers and citizens are thus the guinea pigs in their own collective experiments with new technologies (see Schwarz and Krohn, forthcoming; von Poel, 2009). A poignant formulation of this condition can be found in the report Taking European Knowledge Society Seriously by an expert-group of scholars who study science, technology, and society:

If society is now the laboratory, then everyone is an experimental guinea-pig, but also a potential experimental designer and practitioner. Whose experiments we are involved in, and what is being tested, are mostly confused, blind and inadvertent, and open-ended. We have not yet even acknowledged that this is the state we are in, as a prelude to defining what kinds of experiment, to what ends, under what conditions, are acceptable. Basic democratic principles require that this new realization be acknowledged, and acted-upon. We suggest that in early 21 st century conditions this societally distributed capacity is in need of deliberate development, in the face of intensifying techno-scientific demands on our trust and credulity (Felt et al., 2007: 71)

It is tempting to dismiss as merely metaphorical the notion of collective experimentation in society as a laboratory. But to acknowledge 'that this is the state we are in' requires taking the idea of laboratory experimentation literally (Krohn and Weyer, 1994; compare Groß, Hoffmann-Riem, Krohn, 2005, and Groß, 2009). ${ }^{11}$ As with all laboratories, this one is standardised in a variety of ways, and as with all experiments, these require systematic observation to support a learning process. Though they may enter the experimental condition somewhat unwittingly, societies appropriate new technologies over the course of time by learning to live with them. If the experiment with cellular phones produces a new type and increased frequency of traffic accidents, for example, driving with hand-held phones becomes outlawed and a new generation of car-phones

\footnotetext{
11 These authors acknowledge various precursors to the idea of social and collective experimentation, especially John Dewey, the Chicago School of Sociology, and Donald Campbell. These authors emphasized the merits of bringing an experimental attitude to social learning. In contrast, current discussions emphasize a general condition of societies that cannot confine experiments to the laboratory or other carefully circumscribed situations.
} 
is developed - and the learning process continues with these. For such learning to proceed, however, proper institutions are requires for the more or less systematic observation of the collective experiment. In the case of nanotechnologies, the question of regulation is tied in with the search for such institutions. There is on the one hand the sceptical question whether current methods of data-collection, registration, and monitoring will prove to be adequate; and there is on the other hand the search for new instruments such as codes of conduct, observatories, public engagement exercises, citizens or consumer conferences, and 'ELSA'-research on ethical, legal, social aspects of nanotechnologies. Though vaguely defined and lacking proper agency, these new institutions serve a general form of permanent vigilance. ${ }^{12}$ Without knowing what precisely one is looking for and what small or large catastrophes may loom, these institutions cultivate a general sense of somewhat anxious and simultaneously reassuring preparedness. Just as everyone is a guinea-pig, so everyone is an experimenter or a stakeholder, and all stakeholders are invited to contribute to the responsible development of nanotechnology and thus, everyone is on their toes all the time to jump on issues as they may arise. This generalised attitude takes the form of statements like these: 'We can't promise that nanoparticles will not pose harzards similar to those of asbestos, but we do promise that this time around we would catch this much faster' (compare Gee and Greenberg, 2001).

With open-ended social learning in society as a laboratory arise further questions that concern the ethics and politics of collective experimentation. There is firmly in place a codified ethics for classical experiments that involve human-subjects, especially in the case of clinical trials. These require informed consent, for example, and criteria for the conditions under which the experiment should be discontinued. Sheila Jasanoff (2002) has suggested that for collective experimentation in democratic societies informed consent will need to be replaced by informed dissent - but what shall be done if there appears to be no serious dissent, as in the case of the current world-wide experiment with nanotechnologies (Nordmann and Schwarz, 2010)? And arguably, criteria for calling off collective experiments can be developed from the precautionary principle. But beyond these somewhat superficial suggestions, the analogies and disanalogies between clinical trials and collective experiments should be developed in a more sustained and rigorous manner. In particular, the immersive aspect of experimentation in the laboratories of technoscience and society deserve to be explored. Where the experimenters and observers are also the guinea pigs and vice versa, where

\footnotetext{
${ }^{12}$ At the European Commission and in regard to its proposed Code of Conduct, René von Schomberg views this quite explicitly as institution-building and talks of 'organizing co-responsibility' such that above and beyond participating in 'responsible development of nanotechnologies' stakeholders and societal actors develop obligations towards one another (Schomberg, 2009). It is in this respect that the notion of 'responsible innovation' aims in a similar fashion for the creation of corporate accountability (Davies, MacNaghthen, Kearnes, 2009). For a methodological reconstruction of 'permanent vigilance' in the context of social learning and ecological design see also Groß (2010).
} 
experiments do not serve the advancement of truth but the experience and management of surprising features and effects, the mode and manner of experiencing and observing the experiments becomes crucially important.

\section{b) Observatories and other Agencies}

To be sure, any kind of intervention in a social context can be considered an experiment. Whether or not this is appropriate depends entirely on the extent to which one can take this label literally. ${ }^{13}$ One way of taking the label literally was illustrated just now and consists in pursuing the ethics of human experimentation at the different scales of clinical trial and collective experiments. Others ways have been proposed by social reformer Jane Addams in 1909, by the Chicago School of sociology which considered the city as a site for social experimentation, and by Donald Campbell who developed a detailed program for treating social and political reforms as experiments - here, the systematic variation of parameters and comparison to controls plays a role (Groß, 2009; Park, Burgess, McKenzie, 1925; Campbell, 1969). For the present purposes and for the philosophy of nanotechnoscience, the notion of collective experimentation is inextricably bound up with the regime of vigilance, that is, with a more or less systematic way of observing the experiment in order to learn from it, if only by way of ad hoc adjustments in real time.

Aside from asking what scientific and technoscientific experiments are and how nanoscale researchers engage in experiments, philosophers have been interested in the question of observation. What is scientific observation and what is going on when scientists or technoscientists observe one of their experiments? Even for observation with the naked eye it has been shown that it is neither passive nor neutral but, in the words of Norwood Russell Hanson (1965), 'theory-laden'. When we see the sun rising and setting, our observation corresponds to an implicit theory when we 'should' be seeing the earth turning against the sun. And when a lay-person looks at a prepared tissue sample, she tends to see nothing at all, whereas the trained eyes of the pathologist comprehend the situation immediately and seemingly without an explicit act of interpretation.

The difficult, perhaps intractable question of immediate, yet theory-laden observation becomes more difficult even in the case of technoscience and in the case of observing the collective experiment with nanotechnologies in society. One of the most famous philosophical essays about scientific observations asks 'Do we see through a microscope?' (Hacking, 1981). In this essay, Ian

\footnotetext{
${ }^{13}$ Compare, for example, the strenuous objection by Günter Anders to consider the introduction of nuclear arms an experiment for (and on) humanity. Since scientific experiments are usually contained in laboratories and since they are meant to be replicable, he found the analogy wholly misleading (Anders, 1980).
} 
Hacking considers light as well as electron microscopy and argues that we might not see 'through' an electron microscope as through a tube but that we see 'with' all advanced microscopes. We see with them because seeing is not merely passive or reactive but is based on strategic interventions: we literally throw light at what we are hoping to see and utilise laws of refraction to receive an image that we can interpret. Therefore even in $19^{\text {th }}$ century light microscopy observation was wrapped up with an experimental intervention of sorts. And though electron microscopy might appear more mediated and inferential than light microscopy, this does not make it less reliable: indeed, one of the ways in which electron microscopy is highly inferential is the fact that it is calibrated to light microscopy: electron microscopy is set up in such a way that it agrees with light microscopy. So even where, in the end, one does not look through a lense but at a display screen, the display gives us a way of seeing the world much as a television set does. For the expert, then, scientific observation involves a technically contrived effortlessness or mediated immediacy - it is conceptually complicated and perceptually simple.

With regard to nanotechnologies, Hacking's question should now be extended to read 'Do we see through a scanning tunnelling microscope'? One of the distinctive features of the STM is that it is used to intervene not only by making visible but also by way of manipulating the objects under observation. ${ }^{14}$ One of the earliest publications about nanotechnology featured one of Don Eigler's famous STM images and notes in the caption: 'Using a tool known as a scanning tunnelling microscope (STM), the wave nature of electrons becomes visible to the naked eye. Here, the electrons are confined by a ring of 48 atoms individually positioned with the same STM used to image them' (Amato, 1999: 2). A second distinctive feature of STM microscopy consists in its twofold calibration. Its data set is calibrated to electron microscopy on the one hand, and on the other hand its visual output is calibrated to topographic software that is used in geography, simulation modelling and video gaming - this software is best suited for the representation of what goes on at the surface of a body. Aside from providing the pleasure of experiencing a very familiarlooking space that stands ready to be colonised by nanotechnology, it stacks the deck in favour of inferences from the likeness of STM-images and theoretical models in a computer simulation. Tellingly, these distinctive features make the STM conceptually even more complicated but perceptually even simpler than electron microscopy. In a recent interview, one of the inventors of the STM therefore notes as the most striking feature of nanotechnology that for a new generation of

\footnotetext{
14 To be sure, electron microscopy can also be used to displace individual atoms. But in contrast to scanning tunnelling and atomic force microscopy, this capability does not enter into questions regarding the reliability or trustworthiness of the observational tool.
} 
scientists 'playing with atoms' has become perfectly straightforward ${ }^{15}$ - because perceptual ease and ease of manipulation makes one forget all the conceptual complicatedness.

Philosophers tell different stories when they consider whether the case of the STM is just another small step in the history of microscopy or whether it poses entirely new questions (see, for example, Pitt, 2004; Rehmann-Sutter, 2008). But they all agree that it involves an interplay between active intervention and passive submission or, to put it philosophically, between spontaneity and receptivity. Indeed, this attitude of the observer informs the general orientation towards objects of nanoscale research: interesting properties that might provide technical functionality are actively sought out by researchers who are hoping to be surprised by the phenomena they produce. Also, the appearance of specific phenomena and processes requires hard work and careful control, but the familiar visual frame of the 'surfacescape,' for example, opens up an unbounded space for the emergence of novelty and surprise.

This interplay is probably not new or specific to nanotechnologies but it holds equally for observational control at the nanoscale and for 'observational control' of the publics that are required to support and maintain nanoscale research. At this point in time, observation of the collective experiment consists mostly of luring unsuspecting publics into a space of technical possibility and confronting them with long lists of possibly forthcoming applications of nanotechnology. Therefore, various observatories of nanotechnology are not so much observing the collective experiment but noting technological trends and promises and, at best, attendant public expectations and anxieties. Where politically minded publics call for systematic and enforceable oversight and regulation, these observatories retreat to something much weaker than that. ${ }^{16}$ However, since due to the complexities of nanoscale phenomena classical regulatory approaches might fail to gain traction, a more rigorous mode of observation and thereby a more deliberate form of collective experimentation and social learning appear to be required.

A rather principled philosophical consideration may have very practical implications for the development of an appropriate model of observation. If one reconsiders the history of 'seeing with microscopes' one might say that much of it was concerned with realism or truth: Straightforward seeing is associated with seeing how things are, whereas a highly theory-laden and inferential mode of perception suggests that what we see is a construct of sorts. ${ }^{17}$ The reliability of a way of seeing -

\footnotetext{
15 The statement by Gerd Binnig has been on view at the Expedition Zukunft mobile science exhibition organized by the Max Planck Gesellschaft during 2009 in Germany.

${ }^{16}$ See Gammel, Lösch, Nordmann (2009) on various models of 'observation' that have been implemented on a variety of observatories.

17 To be sure, more sustained reflections of microscopy indicate that the question about realism and truth is based on a misleading dichotomy. For much instrument-aided observation one can say that it does not provide straightforward access to something given, but that it is not therefore an inferential construction of something contrived.
} 
with the electron microscope, for example - was judged in comparison to apparently straightforward cases of immediate perception. But the two features of the STM drive home that the reliability of the observation depends not on representational features but on the technical robustness and performance of the system. Though STM microscopy is even more inferential than electron microscopy, the fact that it is also an instrument of intervention and the fact of its twofold calibration indicate that it cannot be likened to a human observer who confronts an outside reality and wonders whether a mental image provides a truthful representation. Instead, the STM is coordinated with a multitude of other instruments and procedures and is judged by the way it agrees with and improves upon a whole system of observational and experimental techniques. Firmly entrenched in a variety of contexts and practices, the STM is not so much a method of seeing atoms on surfaces but an 'apparatus-world complex' that affords perceptual and manipulative access to atoms on surfaces. ${ }^{18}$ Similarly, collective experimentation with emerging nanotechnologies also requires a robust system of observation that is tied to various institutions and interests and that is simultaneously a way of seeing and of acting in the world. Rather than registering potential hazards and public concerns, a systematic observation of our collective experiments should afford a kind of institutional robustness or a system of tracking and steering nanotechnological developments. When, for example, a commercial 'nano'-product sends users to the hospital for respiratory distress, an observation of this event should do more than merely represent what happened - what did the media report, what did the toxicologists conclude, how did the stock market react. Instead, it needs to view this incident as an experimental situation that served to probe the robustness of the regime of vigilance that is to ensure a social learning process - how effectively did existing regulatory institutions, governmental agencies, public media and the scientific community respond to this incident, what was learned and what deficits can be identified? To make these assessments, to raise and answer these questions, an appropriate institution is needed.

\section{CONCLUSION}

When politicians, NGOs or citizen panels call for the regulation of nanotechnology, they often have a rather simple and familiar picture in mind: If products come to market with nanotechnology inside, regulatory tools should offer assurance that all marketed products are safe. The philosophy of nanotechnoscience tells us that this expectation will not be met - not simply because of the

\footnotetext{
18 See Rom Harré for an account of the difference between instruments that function like probes (the thermometer, the light microscope) and a complex of apparatus and world that makes a phenomenon available for research and development, for observation and intervention. Of the latter complexes he says that they afford a phenomenon much like yeast, water and an oven afford us a loaf of bread (Harré, 2003).
} 
heterogeneity of all the various technologies, processes, or products that might come under the heading of 'nanotechnology.' It is not at all clear what it means for a product to have nanotechnology inside: Does it contain nanoparticles and, if yes, are these nanoparticles sufficiently alike to afford general statements about their toxicological properties in the various places where they might end up? Were nanotechnological processes used in the manufacture of this product and how, if at all, did these change the properties and behaviours of the product? Does the product have nanostructured surfaces that might interact with biological systems? Do the slightest variations within the margin of tolerance for the manufacture of any two samples of the same product make a relevant difference regarding their properties and behaviours? Such questions and the more general considerations stated above indicate that the kind of knowledge that can be acquired about nanotechnoscientific objects does not allow for general conclusions about definite behaviours including the health-effects of large, well-defined classes of things. As has been suggested in these pages, the reason for this can be found in the nature or ontology of those objects, in the complexity of interactions at the nanoscale, and in the orientation of nanotechnoscience towards surprising properties and technical possibilities rather than structural constraints and an assessments of limits.

The news is not all bad, however. Where regulation, classically conceived, cannot gain traction, one does not therefore need to retreat all the way to passive observation of technological trends, citizens' concerns, or the collective experiment with nanotechnology. Instead, the practices of nanotechnoscience and the notion of collective experimentation suggest strategies for strengthening the regime of permanent vigilance. For example, scanning probe microscopy provides a model for an observational practice that is conceptually intractable and that leaves many questions about representational accuracy unanswered but that is nevertheless reliable and robust. Similarly, one might envision a 'scanning probe agency' as an institution of permanent vigilance which permits monitoring and intervention without relying on the availability of knowledgeable risk assessments. ${ }^{19}$ This agency works by scanning the 'surfacescape' of nanotechnological trends and developments, programs and debates, and by rigorously probing within this horizon experimental situations that test the capability of society to deal effectively with nanotechnologies. It thereby develops deliberative capacities that allow for active intervention in the societal and technical development of nanotechnologies. But regardless of whether some such model becomes implemented or not, there is a middle ground between classical regulation and the various voluntary schemes of soft law. It can be found by probing the robustness of a system of institutions,

\footnotetext{
${ }^{19}$ For a more extensive development of this particular proposal see Lösch, Gammel, Nordmann (2009).
} 
observational techniques, and vigilant stakeholders that are implicated in our collective experiment with nanotechnologies. ${ }^{20}$

\section{CONTACT}

Alfred Nordmann

Professor of Philosophy

Technische Universität Darmstadt

Residenzschloss, 64283 Darmstadt, Germany

nordmann@phil.tu-darmstadt.de

\section{REFERENCES}

Amato, I. (1999), Nanotechnology: Shaping The World Atom By Atom, Washington, DC: National Science and Technology Council.

Anders, G. (1972), Endzeit und Zeitende: Gedanken über die atomare Situation, München: Beck.

Anders, G. (1980), Obsolescence of the Human, London: Radius.

Baird, D. (2004), Thing Knowledge: A Philosophy of Scientific Instruments, Berkeley: University of California Press.

Belting, H. (2001), Bildanthropologie. Entwürfe für eine Bildwissenschaft, München: Fink.

Binnig, G. (1992). Aus dem Nichts: Über die Kreativität von Natur und Mensch, Munich: Piper.

Campbell, D.T. (1969), 'Reforms as Experiments,' American Psychologist, 24, 409-429.

Davies, S., P. Macnaghten and M. Kearnes (eds.) (2009), Reconfiguring Responsibility: Lessons for Public Policy (Part 1 of the report on Deepening Debate on Nanotechnology), Durham: Durham University.

Felt, U. et al. (2007), Science and Governance - Taking European Knowledge Society Seriously, Luxembourg: Office for Official Publications of the European Communities.

Galison, P. (1997), 'Material Culture, Theoretical Culture and Delocalization', in John Krige and Dominique Pestre (eds), Science in the Twentieth Century, Amsterdam: Harwood, pp. 669-682.

Galison, P. (2006), "The Pyramid and the Ring", presentation at the conference of the Gesellschaft für analytische Philosophie, Berlin, February.

Gammel, S., A. Lösch and A. Nordmann (2009), Review and Report of Existing and Proposed Observational Initiatives, Brussels: ObservatoryNano project.

\footnotetext{
${ }^{20}$ Along with the discussants at a July 2009 seminar organised in Canberra by Laura Cabrera and John Weckert, I would like to thank Diane Bowman, Stefan Gammel, Matthias Groß, Andreas Lösch, and Marianne Ward for critical and constructive comments.
} 
Gee, D. and M. Greenberg (2001), 'Asbestos: from 'magic' to malevolent mineral', in Paul Harremo, David Gee, Malcolm MacGavin, And Stirling, Jane Keys, Brian Wynne and Sofia Guedez Vaz (eds), Late lessons from Early Warnings: The Precautionary Principle 1896-2000, Copenhagen: European Environment Agency, pp. 52-63.

Groß, M. (2009), 'Collaborative experiments: Jane Addams, Hull House and experimental social work', Social Science Information, 48(1), 81-95.

Groß, M. (2010), Ignorance and Surprise: Science, Society, and Ecological Design, Cambridge: MIT Press.

Groß, M., H. Hoffmann-Riem, and W. Krohn (2005), Realexperimente: Ökologische Gestaltungsprozesse in der Wissensgesellschaft, Bielefeld: Transcript.

Hacking, I. (1981), 'Do We See Through a Microscope?', Pacific Philosophical Quarterly, 62, 305-322.

Hanson, N.R. (1965), Patterns of Discovery, Cambridge: Cambridge University Press.

Harré, R. (2003), 'The Materiality of Instruments in a Metaphysics for Experiments', in H. Radder (ed), The Philosophy of Scientific Experimentation, Pittsburgh: The University of Pittsburgh Press, pp. 19-38.

Jasanoff, S. (2002), 'Citizens at Risk: Cultures of Modernity in the US and EU', Science as Culture, $11,363-380$.

Krohn, W. and J. Weyer (1994), 'Society as a Laboratory: The Social Risks of Experimental Research,' Science and Public Policy, 21(3), 173-183.

Lösch, A., S. Gammel and A. Nordmann (2009), 'Observe-Probe-Regulate: Embedding Nanotechnological Developments in Society', in Stefan Gammel, Andreas Lösch, Alfred Nordmann (eds.), Jenseits von Regulierung: Zum politischen Umgang mit der Nanotechnologie, Heidelberg: Akademische Verlagsgesellschaft, pp. 3-15.

Mitchell, W. (2005), What do Pictures Want? The Lives and Loves of Images, Chicago: University of Chicago Press.

Nordmann, A. (2004), 'Molecular Disjunctions: Staking Claims at the Nanoscale', in Davis Baird, Alfred Nordmann and Joachim Schummer (eds), Discovering the Nanoscale, Amsterdam: IOS Press, pp. 51-62.

. (2006a), 'Collapse of distance: Epistemic Strategies of Science and Technoscience;, Danish Yearbook of Philosophy, 41, 7-34. 
— . (2006b), 'Noumenal Technology: Reflections on the Incredible Tininess of Nano', in Joachim Schummer and Davis Baird (eds), Nanotechnology Challenges: Implications for Philosophy, Ethics and Society, Singapore: World Scientific Publishing, pp. 49-72.

— . (2006c), ,'Vor-Schrift - Signaturen der Visualisierungskunst'. in Wolfgang Krohn (ed.), Ästhetik in der Wissenschaft: Interdisziplinärer Diskurs über das Gestalten und Darstellen von Wissen, Hamburg: Felix Meiner, pp. 117-129.

— . (2008), 'Philosophy of Nanotechnoscience', in Günter Schmid (ed), Nanotechnology: Volume 1: Principles and Fundamentals, Weinheim: Wiley, pp. 217-244.

(2008), 'Technology Naturalized: A Challenge to Design for the Human Scale,' in Pieter E. Vermaas, Peter Kroes, Andrew Light, and Steven A. Moore (eds), Philosophy and Design: From Engineering to Architecture, Dordrecht: Springer, pp. 173-184.

Nordmann, A. and A. Schwarz (2010), 'Lure of the 'Yes': The Seductive Power of Technoscience,' in Mario Kaiser, Monika Kurath, Sabine Maasen, Christoph Rehmann-Sutter (eds), Assessment Regimes of Technology: Regulation, Deliberation \& Identity Politics of Nanotechnology, Dordrecht: Springer, pp. 255-278.

Park, R.E., E. Burgess, R. McKenzie (1925), The City, Chicago: University of Chicago Press.

Pitt, J.C. (2004), 'The Epistemology of the Very Small', in Davis Baird, Alfred Nordmann and Joachim Schummer (eds), Discovering the Nanoscale, Amsterdam: IOS Press, pp. 157-163.

van de Poel, I. (2009), The introduction of nanotechnology as a societal experminet, in Simone Arnaldi, Andrea Lorenzet, and Federica Russo (eds.), Technoscience in Progress: Managing the Uncertainty of Nanotechnology, Amsterdam: IOS Press.

Rehmann-Sutter, C. (2008), 'Viewing the Nanoscape; Implications of AFM for an Ethics of Visualization,' in Johann S. Ach and Beate Lüttenberg (eds), Nanobiotechnology, Nanomedicine and Human Enhancement, Münster: LIT Verlag, pp. 27-44.

Rip, A, and C. Shelley-Egan (2009), Positions and responsibilities in the "real" world of nanotechnology, unpublished manuscript.

Roco, M. (2003), 'Broader societal issues of nanotechnology', Journal of Nanoparticle Research, 5, $181-189$.

Roco, M. and W.S. Bainbridge (ed) (2001), Societal Implications of Nanoscience and Nanotechnology,Arlington, Virginia: NSET Workshop Report.

Roco, M. and R. Tomellini (eds) (2002), Nanotechnology Revolutionary Opportunities and Social Implications Workshop, Lecce, 31 January - 1 February 2002.

von Schomberg (2009), 'Organizing Collective Co-Responsibility: On Precaution, Knowledge Assessment, and Codes of Conduct', keynote lecture at the annual meeting of the Society for the Study of Nanoscience and Emerging Technologies, Seattle, September. 
Schwarz, A. and W. Krohn (forthcoming), 'Experimenting with the Concept of Experiment: Probing the Epochal Break', in Alfred Nordmann, Hans Radder and Gregor Schiemann (eds), Science and Its Recent History: Epochal Break or Business as Usual?

Winsberg, E. (2006), 'Handshaking your way to the top: Inconsistency and falsification in intertheoretic reduction', Philosophy of Science, 73, 582-594.

ـ (2009), 'A tale of two methods', Synthese, 169, 575-592. 